\title{
Computing Behind the Iron Curtain and Beyond Hungarian National Perspective
}

\author{
Maria Raffai \\ Chair for Information Science, Szechenyi Istvan University, \\ Egyetem ter 1., 9026 Gyõr, Hungary, http://www.sze.hu \\ <raffai@sze.hu>,http://rsl.sze.hu/ raffai
}

\begin{abstract}
At the beginning of the computing era it was a great challenge to write a running program in order to solve different mathematical, statistical tasks, and to get the appropriate results by using a computer. At the university where I had began my studies we started to get acquainted with computers using a Russian made machine, named URAL 2. Looking back to the roots and thinking of the Hungarian born pioneer of computer science: the polymath John von Neumann, I had intended to deal with the history of computing at the very beginning of the eighties. Although there is a wide range of computing history literature worldwide (most of them in English), there are not any publications dealing with the Hungarian results. As I was one of the first graduates on computing taught by the Pioneers, I am forced to perform research on all materials dealing with the Hungarian achievements in computing, to protect the values of the past as long as it is not too late and also to make the results known!
\end{abstract}

\section{Historical Background}

In order to understand the evolution process, to see the efforts and difficulties this country has undergone during the realization of her purposes the main streamline had always been to comprehend the political background. The end of the Second World War resulted with a situation, which had great influence on both the social and the technical evolution. The world was divided into two parts; the government of the Soviet Union directed the Socialist Block. Because of this status the countries belonging to this authority were blocked from the achievement of the other parts of the world, and could produce development and go forward only with difficulties. Hungary belonged also to this block. Though Hungary has had several relations to 
western enterprises and professionals, the main line of the research and the innovation was directed by the Soviets up to the end of eighties. But telling the truth at the beginning of the eighties the situation started to turn more liberal, the relations could open wider even towards the western countries and the United States. The experts and some university students could take study tours to foreign countries outside the socialist block, and there was also possibility to purchase computers from all over the world.

\section{Computing Eras}

Although the computing evolution process is reckoned from the end of the Second World War, the roots of building automatic working machines in Hungary lead us back to the $18^{\text {th }}$ Century when Farkas KEMPELEN had developed and built a speaking machine (1773) and a chess automat (1796). Later then Ányos JEDLIK discovered the theory of self-induction and the dynamo principle (1861). He was also the first who constructed electromagnetic rotating machine. But to our great regret Hungary could never become known of their scientific issues; therefore the discovery of dynamo is assigned to Werner Siemens (1867). The next considerable innovative results worth to mention were the automatic airdefence fire controller and the targeting unit designed by István JUHÁsz (1925-1939). After a successful show in Sweden (1932) the GAMMA Inc. produced more then 1000 targeting units and sold in several foreign countries 0,0 .

\subsection{The five-era view of computing in Hungary}

Looking back to the evolution of Hungarian computing we can distinguish five eras as it is shown on Figure 1. But for the reason that a conference paper is only a frame to prescribe scientific research results, it is impossible to give full details on the discussed theme, so I have to focus only on some very important milestones not losing sight of the inherences. Let us see the main characteristics and the most important events/achievements! 


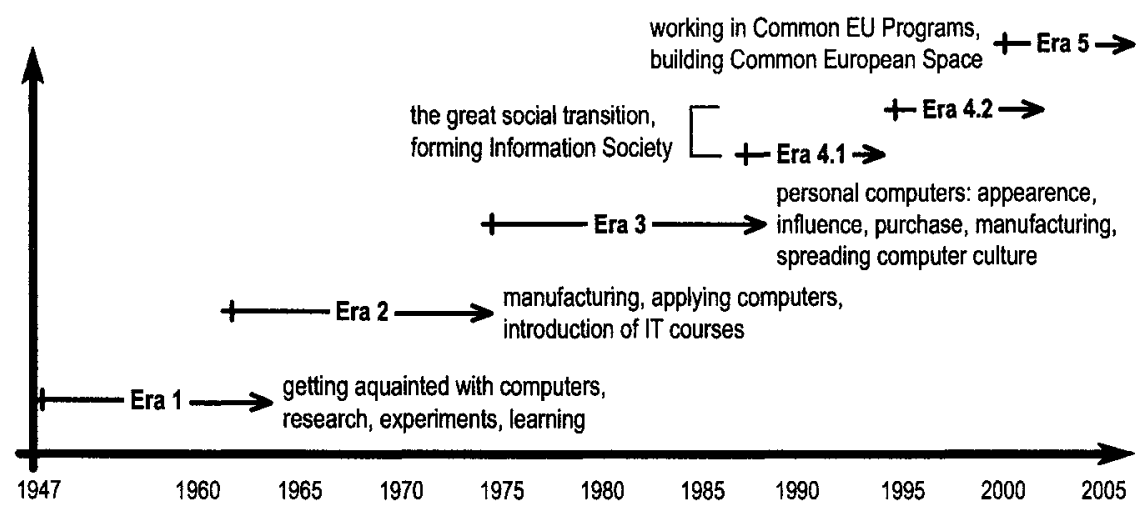

Figure 1. The Five-Era View of Computing Evolution in Hungary

\subsection{The beginnings up to 1964}

The first epoch can be dated back to 1947-1964. At that time some electrical engineers, mathematicians and economists had started to get acquainted with the principles of electronic calculators and with the new technique. They tried to gather information about the first built computers and they performed uncountable research work and conducted experiments in different laboratories. The research and experimentation work was strongly influenced by John von Neumann's activity; by the first computers having built in the USA ${ }^{1}$, by the documentations about the computers having developed in Europe and also in other parts of the world but mainly in the Soviet Union.

The first László KozMA's calculators were created in 1936. Their improvements such as the quick calculating machine of the telephone exchange elements, the remote controlled solution via telex line or the magnetically wired transfer memory were designed and manufactured at the Antwerpen Bell Telephone Company. Returning back to Hungary in 1943 he continued his research on telephone networks at the Technical University of Budapest where he constructed the first Hungarian Computer named as MESz-I using a digital binary signal-receiving system (1976).

László KALMÁr first started to be interested in the central problems of mathematical logic and set theory, and by 1956, he developed the idea of building a logical machine. This machine used logical operations such as conjunction, disjunction and negation for evaluating the true value of formulae containing logical variables. As performing tools, he used an electric circuit made solely switching

\footnotetext{
${ }^{1}$ The first translation about the architecture of ENIAC was published in the Hungarian Scientific Journal in 1947. The article was prepared by Tihamér NEMES, who also developed a mechanical logical machine in 1954.
} 
elements. By the end of the 1950s, an idea came up for constructing a computer, which directly performs a program written in a high level programming language. Kalmár started to work on the principles of such a computer and designed it in great details. Later a research team in Szeged University directed by Dániel MUSZKA improved these designs as a formula directed computer (1960). Beside developing logical machine Kalmár and Muszka created a sensor controlled memory model of conditional reflex in the form of a ladybug. This artificial animal model is still working.

The efforts to build a Hungarian computer with similar characteristics as the ones constructed in the US - as for instance the ENIAC - were launched in 1956 with the KKCS (Cybernetic Research Group) established as an institute of the MTA (Hungarian Academy of Sciences). The group was designated for building a computer produced by fully Hungarian design, named by B-1 as the smaller version of the ENIAC. However, as the team had lacked the practical experience they asked for the help of the Soviet engineers. Finally, by the common ascent the KKCS had the task to build a middle-sized computer, the $M-3$ on the basis of Soviet plans. The head of the development was Bálint DöMÖLKI (now he is the member of the IFIP General Assembly). The computer that was built in two Years from 1957 could perform 50 operations per minute, its magnetic drum capacity was 1024 words and data input worked with punched tape. This machine used to work first in a newly established Computer Center, and later it had been moved to Szeged University where it had been working until 1968.

Being proud of the achievements of my motherland, it is sorrowful that because of political reasons and/or the lack of any chance to make success and gain acknowledgement some of Hungary's very valuable scientists had felt to be forced to leave Hungary to follow their own scientific aims, which had the result of being known worldwide. Nevertheless, those who remained at home had no possibility to acquire the same world/regional-fame.

\subsection{Computers in Work and Manufacturing: Epochs between 1964-1989}

After having built the first computers in Hungary, there was a very progressive developing and manufacturing process under way. As the first step in this process it is worth to reference a computer for supporting data processing and administration constructed in the Hungarian Telephone Factory by László EDELéNYI and László LADO in 1959. After having built the prototype of EDLA-I the engineers constructed the next generation that used already transistors. The most remarkable element of this computer was the foil memory developed by Tibor SZENTIVÁNYI and Ottó BÁNHEGYI, which can be regarded as the ancestor of the floppy disc.

In the process of scientific and physical $\mathrm{H} / \mathrm{S}$ development several Hungarian enterprises played very important role. Not aspiring to entirety we have to mention 
the VILATI, KFKI, MOM, Videoton, BRG and the SZKI. In these factories computers and peripheral units had been designed and produced. Let us list some mass-produced devices:

1964 Hunor Calculator and EMG-830 computer (EMG Co.)

1969- Production of TPA-series as the clone of Deck's PDPs: TPA-1100, TPA1140 (PDP-11 and VAX-11), the IC-based TPA models (following the architecture of the PDP-8 family; all developed and produced by KFKI)

1970- Production of the R 10 minicomputer (Videoton Co.), disk units and floppy disk drives (MOM)

1982- Exporting software to the western countries and manufacturing of the first Hungarian developed personal computers (SZKI/Sci-L), and produce of personal computer for schools: the HT school computer (Híradátechnika Co-operative) and the PRIMO home computer (MTA SZTAKI)

Beside using Hungarian made computers and despite of COCOM limit, this small socialist governed country had always found the possibility to procure computers of excellent qualification from different foreign countries. At the end of the sixties some ICL, IBM, Siemens, CDC, BULL, Elliott computers had been purchased and used for the industrial, research and state administration works. As at that time there were not enough well trained technicians and software experts for maintaining and repairing computer failures the computer centers required professional help. In order to satisfy this demand and giving quick aid a nationwide enterprise with county affiliations had been founded (SZÜV).

Clearly understanding the history on computing in Hungary, looking back to the computer manufacturing, it is essential to mention the political and economic changes in 1968 (New Economic Mechanism of Hungary) as the most remarkable program of the East European socialist block. In the same Year on the conference managed by the Soviets the social countries what at that time had belonged to the KGST decided to produce her independently designed computers in country-level cooperation, sharing the manufacturing work of the products. In the frame of the ESZR named program the Soviet Union produced the central processing unit of the R-20, R-22 and R-40 computers (semi-compatible with the IBM S 360/40 and 370 Series), Bulgaria was signed to produce the disk units, East Germany to Robotron series, and Hungary to the displays and the R-1x series of mini computers (R-10, R12 and later R-15).

With putting more and more produced and also purchased computers into use the demand for people who taught and learned computing, who developed applications and even for those who used them on effective way was progressively increasing. During the second half of the 1970s, the number of such professionals was quickly growing. Characterizing the results and the consequences of the second and third epochs in the Hungarian computing it can be stated, that by the end of the 
eighties the employees and the pupils had got accustomed to the computers, learned how to use them, and they also could already take advantage of their capability.

\subsection{The home computer craze}

The early 1980s brought significant changes in the attitude and also in usage of computers. The appearance of the personal computers such as ZXs, Commodores, and later the Hungarian made HTs and PRIMOs became more and more popular, and instead of being afraid of the computer centers with closed doors the leaders started to familiarize themselves directly with the PCs. At that time, they thought that the personal computers will solve their business problems, and that they do not need the mainframes anymore. However, this conception was condemned to death because of the lack of solutions for storing and managing the necessary amount of data.

But anyway, the use of home and personal computers no matter if they were purchased or produced, played very important role in computerization in Hungary! As the State Administration introduced an effective supporting system in the school year of 1982-1983 by what the secondary/high schools could get at least one, but in average more school computers, not only the university students could get acquainted with computers and their usage but the computers became friends of every schoolboys and -girls. It is unambiguous that this school computer program was the first step to a paved way for spreading general computer literacy in Hungary!

Beside the school computer program there have been proved results also in hardware and software R+D activity as the scientists and engineers achieved internationally recognized results. The home graphical color display designed by SZTAKI, the ArchiCAD program, the optical character recognition system (Recognita software), the image processing systems, the MPROLOG used for expert systems are the most well known competitive achievements had been sold on the world market.

\subsection{The great socio-political transition}

The last decade of the $19^{\text {th }}$ Century brought significant changes in Hungary. The most remarkable and important to mention was the secession from the Soviet Union's socialist system and transform into a capitalistic system. It was a great shock not only for the individuals but also for the companies, administration and the different institutes. That means that the decade of the nineties brought significant changes not only in the social economic system but also in computing in Hungary.

The transition concerning to the electronization has began with the MTA's Information Infrastructure Development Program (IIF or $1^{2} \mathrm{~F}$ program). This program was declared after approving the Hungarian Information Strategy, and 
served as the basis for modernizing the information infrastructure in the research and development processes and in the academic and university communities. In the scope of this program fighting with realization problems the infrastructure and support services achieved the acceptable technical and organizational level with those of the most European countries. After having deployed the majority of the available network resources between the Years of 1990-1994 the services of eMail and message handling, the file transfer, remote job entry and interactive processing, the bulletins and the distribution lists have been already accessible. In early 1996 already about 80,000 users $^{2}$ had access to the internet, we had altogether 17,000 hosts connecting to it, and we had altogether 10000 email addresses. The IIF program is continuously updated -let the target community be young or elder-it has also newer and newer plan elements in order to give the Hungarian population the possibility to join accessible to the international electronic circulation.

\section{Computer Science in Education}

\subsection{The pioneer universities}

The scientific and engineering background gave a stable base for special courses in the frame of the high education institutes. The first attempts took place in Szeged, from that time revoked as "the cradle of education of computing", where a cybernetic seminar was announced in 1956 followed by a course for program designer mathematicians already in 1959. The mathematicians could get computer skills on the deployed M3 (from 1963), on a Minszk-22 computer (from 1968), and later they became acquainted with the R-40 (from 1975), which was the social semiclone of the IBM System 370. The "Szeged School" created and directed by professor Kalmár played a definitive role in the Hungarian computerization process. Having excellent conditions (professors and computers) the JATE named University at Szeged was the first one in Hungary, which got afloat courses in the field of Computer science in the Academic Year 1960-1961. Parallel to Szeged the Budapest Technical University (BME) having also a good technical basis with MESZ-1 computer (1958) could also start very early with programmer training.

At the beginning of the sixties a very intensive innovation started in the application of computers not only in business and administration but in the academic sphere as well. Most of the universities received the opportunity to purchase computers in order to apply them in scientific research and education. For the initiatives of Béla KREKÓ the University of Economics (MKKE) deployed the

\footnotetext{
${ }^{2}$ The population of Hungary was at that time around ten million.
} 
Russian made URAL 2 computer in 1960 and started with the course for mathematician planners. Nowadays we call this kind of education as a course on business information science. In some years, the most significant universities joined the education programs in computing. The Eötvös Lóránd University of Sciences (ELTE; 1961), the University of Debrecen (a Poland made Odra 1013 in 1963) also belonged to the pioneer institutes.

From national budgetary reasons it was impossible to support all the universities with expensive computers, the Ministry of Education established a University Computer Center in 1964 in order to serve the administrative and research work of every institutes. Beside the effective settled tasks the Center, named ESZK played a very important role in making the computing culture general.

\subsection{The first special courses}

During the eighties already many Hungarian enterprises had been deployed and used computers to support data processing, to solve operation research problems and the administrative and management tasks, so there was an urgent need to find highly trained, erudite professionals in the field of computer science. In order to satisfy this demand and to give professional help in installing and serving computers an institute was established in 1972. The SZÁMOK international education center of informatics (later it has changed to SZAMALK) was dedicated to train the professionals on the different field of IT such as system analysts and designers, programmers, operators, technicians etc. In this period more than 6500 students was graduated and received diploma yearly, and nowadays this institute fulfills the requirements with 20000 students even from 50 foreign countries.

\subsection{Educational process fulfillment}

The early courses focused mainly to teach computer programming first in machine code, in Assembly, and later in ALGOL, Fortran and/or Cobol. As these courses specialized mainly for training electrical engineering, mathematics, programming and economic with specialty of applied mathematics they organized trainings to develop practice mainly in writing and testing programs not taking care of the platform-independent logical design of the problem. Despite of having at the first time only elementary knowledge on computing the professors and the assistants obtained skills in teaching. As a result, during the years, excellent experts had been growing up and by the end of the $1980 \mathrm{~s}$, the situation was mature enough to introduce special computer courses at every universities and colleges. In the curriculums, we can recover all subjects relating to the different special fields of ICT such as information system design, system and software development methodologies and tools, operation system concepts, computer and network 
architecture, data modeling and database design, CASE tools, programming languages etc.

By the end of the nineties about 4,000 students graduated yearly in Hungary in the different fields of computing. Most of them got their degree at technical universities and colleges, $45.5 \%$ of them had advanced degrees. As it can be seen from the Table 3, most of the graduates are specialized in technological knowledge (almost $75 \%$ ), $20 \%$ in program designer, and only $5.8 \%$ in business related areas.

Table 3. The Number of Students Graduated in Computing

\begin{tabular}{|l|c|c|c|c|}
\hline Course/Degree & $\begin{array}{c}\text { Univ. } \\
\text { Degree }\end{array}$ & $\begin{array}{c}\text { College } \\
\text { Degree }\end{array}$ & Sum & Ratio \\
\hline Technical informatics & 970 & 1990 & 2960 & $74.74 \%$ \\
\hline Program designer mathematician & 600 & 170 & 770 & $19.44 \%$ \\
\hline Business information systems & 130 & 0 & 130 & $3.28 \%$ \\
\hline Programmer w. spec. in economics & 100 & 0 & 100 & $2.52 \%$ \\
\hline & 1800 & 2160 & $\mathbf{3 9 6 0}$ & \\
\hline & $45.50 \%$ & $54.50 \%$ & & $100 \%$ \\
\hline
\end{tabular}

In the existing higher education structure, the leading universities justify their degrees based on market demands, and add permanently new courses to the existing set. Although these courses show only small differences instead of harmonizing the knowledge structures of the curriculums the different programs competed for the students what caused great divergences in skills, qualification and degrees, and made almost impossible for the students to switch their study field and path, and try to make their institutions more attractive. Some additional factors underlined the urgent need for a wide coordination not only inside the country but even wider in whole Europe:

- The budget is almost $100 \%$ government funded, so the degree of financial support strongly depends on the lobbying of the university leaders.

- The existing IT infrastructure of the universities is very heterogeneous.

- The students' skills and experiences in using computers are in most cases limited to personal computers and to access to the internet.

- The level and currency of professors' knowledge is different: there are even institutes without adequately qualified teachers.

- There is great lack of high quality instructors because of low salary.

- The teaching materials (books, supplements, lab manuals, exercises, case studies etc.) are missing or they are outdated.

- The existing dual system makes impossible to move between programs or from one university to another.

- The quality assurance process is exhausted and stops with the accreditation. 


\subsection{The common European Space on Higher Education}

The great breakthrough in higher education system started in 1999 when the education ministers of 29 European countries signed the Bologna Declaration in order to harmonize the European education systems and unify the degrees. The ultimate goal was to create a common European Higher Education Space by 2010 with performing competitiveness in six objectives: (1) Easily readable and comparable degrees, (2) Unified degree structure based on a three-cycle model: Bachelor degree, Master's and Doctoral degrees, both as postgraduate degrees, (3) Establishment of a system of credits - such as in the ECTS system, (4) Increased mobility of students and teachers, (5) promotion of European co-operation in quality assurance with a view to develop comparable criteria and methodologies, and finally (6) promotion of the European dimension in higher education: closer international cooperation and networks; language and cultural education. Although the Bologna Declaration strives to unify the education systems in Europe it clearly stated that in the new system the diversity of cultures, languages and educational traditions remains a priority. The universities keep their independence and autonomy, but also underlined that this new system requires constant support, supervision and adaptation to the continuously changing needs.

Replacing the wide variety of IT courses, the Hungarian Committee recommended three courses as the first level of the two-stage education system (BSc): (1) a course for technical computing, (2) a course for program design, and (3) a course for business information systems. Only these programs and degrees will be introduced in the Hungarian higher education system, of course with some considerations to the regional needs and the traditional specialties of the universities. The new courses have been implemented already in the 2004/2005 academic Year.

\section{The Role of the John von Neumann Computer Society}

As the number of computer professionals had been growing by the end of seventies there was and urgent need to establish a forum where the specialists can meet, discuss their problems and results, make the newest issues known, namely change their mind and ideas. After the initiatives in 1968, the John von Neumann Computer Society was founded. The main effort was to bring people dealing with and interested in computers together, to give them chance to publish their experimental and scientific results, to organize presentations, and last but not least, to make computing culture generally possessed. As it is defined in its Constitution the main goals of the society are

- to study computer and information technology,

- to inform the specialists about the new scientific theories and results, the hardware/software solutions and the user's experiences, and bring the parties together, 
- to promote the development of computer science and diversification of the applications,

- to disseminate applications and help to solve current problems,

- to publish the newest results and to organize exhibitions, programs, conferences, lectures and workshops as well as

- to spread the culture of computing, provide education for computer professionals.

The John von Neumann Computer Society is committed in supporting the activity of scientists and also the company professionals by organizing conferences and running workshops as well as by managing regular events through its technical committees. The Society is responsible for supporting the realization of new ideas in computing and for providing the necessary institutional framework for the ITinnovation. The NJSZT is charged to set up and update the law on data base security, to create the Code of Ethics binding on all members, to play a leading role in the nation-wide dissemination of computer literacy and to form the strategy and to give solutions for forming Information Society in Hungary. As a special importance the Society pays particular attention to the young people's education and to spread the information culture among the civil (non IT-professional) population.

The Society not only represents Hungary in a number of international organizations of high prestige, but takes active part in the work of these establishments. Through these relations, the members of the Society can also benefit from participating in international projects. The NJSZT is a member of the IFIP International Federation for Information Processing, the CEPIS (Council of European Professional Informatics Societies), the EFMI (European Federation for Medical Informatics), the IAPR (International Association for Pattern Recognition), the ECCAI (European Coordinating Committee for Artificial Intelligence), the IEEE (Institute of Electrical and Electronics Engineers) and the ECDL Foundation European Computer Driving License. In the past three decades the Society as an active member of IFIP and IEEE played and is still playing through their active members very important role in forming the IT-based modern society in Hungary.

\section{Conclusions}

Summarizing the most remarkable occurrences and the achievements of the Hungarian history on computing we can conclude that in spite of the underprivileged political and economic circumstances the computing evolution can be proud of its results even in international acknowledgment.

Mentioning only the most important milestones I have to highlight the achievement of László KozMA and László KALMÁR, who both later gained the 
acknowledgement of IEEE Computer Society in the form of Computer Pioneer Award in the honour of their academic and technical results (1996).

But being proud of the achievements of my motherland it is sorrowful -that because of political reasons and/or the lack of any chance to make success and gain acknowledgement- some of Hungary's valuable an successful scientists had felt to be forced to leave Hungary to follow their own scientific aims resulted of being known worldwide. But for those who remained at home there was no possibility to acquire the same world/regional-fame.

After having been changed to a competitive and open country of the world in 1989 the computing firms recognized that they could gain profit mainly on assembling hardware from kits (mainly PCs) and from developing software involving added value. The European Union membership (Hungary joined to European Union on the $1^{\text {st }}$ of May 2004) and the activity to form the Information Society forces the Hungarian people to come closer and closer to the developed countries (e.g. USA, JAPAN and EU countries).

Drawing a definitive conclusion from the Hungarian evolution of computing:

I am convinced that the education system and the spreading countrywide computing culture in Hungary are the most important and most significant strength in the survival process.

\section{References}

[1] Kovács, Gy.: Forty Years of the Hungarian Computing and the Volan Elektronika Rt., 1999.

[2] Kovács, Gy.: Old Timers of Computer Technology, International Computer Olympiad, Veszprem, 1996.

[3] Lukács, J.: From the Punched Tape to the Informatics - The TPA History - KFKI GroupMTI, 2003.

[4] Raffai, M.: The Almanac of Computing in Hungary - InForum Publisher, 2000.

[5] Raffai, M.: The Half Century of Computing - Springer Hungarica, 1997. The original title: Az informatika fél évszázada

[6] Szentgyörgyi, Zs.: A Short History of Computing in Hungary - IEEE Hungary Section, Budapest, 1996.; IEEE Annals History of Computing. Vol. 21. No. 31999.

[7] Neumann, J.: First Draft of a Report on the EDVAC - Contract between the United States Ordnance Dept. and the University of Pensylvania (No.: W-670 ORD 4926) 1945. 


\section{Abbreviations used in the paper}

CEPIS: Council of European Professional Informatics Societies

CoCom: Coordinating Committee for Multilateral Export Controls of the nonCommunist Countries during the Cold War

ECCAI: European Coordinating Committee for Artificial Intelligence

ECDL: $\quad$ Foundation European Computer Driving

EFMI: European Federation for Medical Informatics

ESZR: $\quad$ Unified System of Computers (USC)

IAPR: International Association for Pattern Recognition

IEEE: Institute of Electrical and Electronics Engineers

IEEE: International

IFIP: International Federation for Information Processing

JATE: József Attila University of Sciences

KFKI: $\quad$ Research Center to investigate problems of Physics

KGST: $\quad$ Council for Mutual Economic Assistance, the so called COMECON

KKCS: Research Group for Cybernetics belonging to the Academy of Sciences

MOM: $\quad$ Hungarian Optical Factory Inc.

MTA: $\quad$ Hungarian Academy of Sciences

R+D: $\quad$ Research and Development

SZÁMALK: Computer Applications and Service Company

SZKB: Intergovernmental Committee on Computing

SZKI: $\quad$ Computer Research and Innovation Center

SZTAKI: Computing and Automation Research Institute as a Cybernetic Research Group, an institute of MTA

SZÜV: Computational and Data Processing Services Inc. 